\title{
OVULAÇÕES MÚLTIPLAS EM EGUAS ABATIDAS EM PELOTAS-RS
}

\author{
MULTIPLE OVULATION IN SLAUGHTERED MARES - PELOTAS-RS
}

\author{
Claudio Alves Pimentel ${ }^{1} \quad$ Adriana Kroef Tarouco ${ }^{2}$ \\ Anelise Maria Hammes
}

\section{RESUMO}

O presente trabalho descreve a freqüência de ovulaçð̃es multiplas em 3631 éguas, abatidas em Pelotas - RS, durante o período de janeiro de 1988 a setembro de 1989, com a predominância de sangue da raça Crioula. A maior freqüência de ovulaçð̃es múltiplas ocorreu no mês de fevereiro $(19 \%)$, diminuindo progressivamente até setembro $(0,4 \%)$. Este resultado mostra que o fotoperíodo exerce uma influência positiva sobre a atividade ovariana, inclusive no que tange ao número de ovulaçðes por ciclo. A freqüência média geral de ovulaçőes multiplas foi $7,1 \%$ (257/3631). A taxa média de ovulações duplas foi de 6,5\% (235/3631), tripla de $0,5 \%$ (19/3631) e quádrupla, $0,1 \%$ (3/3631). Os meses de dezembro a abril mostraram as maiores freqüências sobre o total das ovulaçóes múltiplas $(65,5 \%)$. Estas informaçðes podem representar um importante subsídio ao manejo reprodutivo da raça crioula, visando controlar o sério problema que as gestaçōes gemelares representam na espécie equaina.
Palavras-chave: ovulações múltiplas, éguas, fertilidade, raça Crioulo.

\section{SUMMARY}

This paper describes the frequency of multiple ovulations in 3631 mares, slaughtered in Pelotas - RS, predominantly from Crioulo breed. The higher frequency of multiple ovulation ocurred in February (19\%), decreasing progressively up to September $(0.4 \%)$. This result shows that the photoperiod has a positive influence on the ovarian activity, even on the number of ovulations per cycle. The overall mean of multiple ovulation was $7.1 \%$ (257/3631). Double ovulations ocurred in $6.5 \%(235 / 3631)$, triple in $0.5 \%(19 / 3631)$ and quadruple in $0.1 \%(3 / 3631)$. The months from December to April presented the highest frequencies over all multiple ovulations (65.5\%). These observations may represent an importante support to

\footnotetext{
${ }^{1}$ Médico Veterinário, Professor Titular, Departamento de Patologia Animal, Faculdade de Veteriária (UFPel). 96010-900 - Pelotas, RS. Autor para correspondéncia.

${ }^{2}$ Médico Veterinário, MSc. (autônomo)

${ }^{3}$ Médico Veterinário, MSc, Professor Assistente do Departamento de Zootecnia, Faculdade de Agronomia, UFPel. 
reproductive management of the Crioulo breed in order to control the serious problem that represents twin pregnancies in equine.

Key words: multiple ovulations, mares, fertility, Crioulo breed.

\section{INTRODUÇÃO}

Um interessante aspecto da fisiologia reprodutiva da égua é a elevada freqüência de ovulações duplas, que, segundo GINTHER (1979), podem chegar a $44 \%$. Essas observações geralmente são documentadas com maior incidência, quando o material experimental é proveniente de matadouro do que quando resulta do exame indireto (palpação retal) já que, nesta segunda metodologia, há uma dependência da habilidade do técnico que realiza a palpação.

Geralmente as éguas ovulam um folículo por cada período de estro, porém, um segundo ou terceiro podem ovular durante o mesmo ciclo estral. $O$ intervalo entre as ovulações é comumente de $\mathbf{2 4}$ horas (sincrônicas) e quando excedem este período são denominadas assincrônicas (HUGHES et al., 1972; STABENFELDT et al., 1975 e GREENHOFF \& KENNEY, 1975).

As incidências de ovulações múltiplas encontradas na literatura são bastante divergentes. Valor tão elevado como o que WARSZAWSKY et al. (1972) encontraram $(42,8 \%)$, contrastam com os relatados por BELLING (1983) que cita limites entre $1,1 \%$ e $20 \%$. Estas diferenças, segundo GINTHER (1986), podem ser atribuídas a fatores como raça, repetibilidade, "status reprodutivo" e idade, assim como, o tipo de metodologia empregada, seja por material de matadouro, palpação retal ou, ainda, pela ultra-sonografia. O mesmo autor, compilando vários estudos, cita uma maior incidência (15 a 22\%) para as raças Puro Sangue Inglês e éguas de Tração, menor para as raças Appaloosa e Pôneis (8 a 11\%) e intermediária para a raça Standardbread (Troteadores) (13 a 15\%). Para a raça Árabe, GINTHER (1982), fazendo uma revisão sobre gestação em éguas, relata que a ocorrência de ovulações duplas não é comum e DESKUR (1985), encontrou uma incidência de apenas $0,8 \%$.

A repetibilidade tem sido relatada em determinadas linhas familiares (GINTHER et al., 1982), bem como para certas éguas individualmente (GINTHER et al., 1982; HENRY et al., 1982).

GINTHER et al. (1982), encontraram que a taxa de ovulaçð̃es duplas foi mais reduzida nas éguas com o "potro ao pé" (6\%) do que as categorias virgem e vazia no ano anterior (16\%). HENRY (1981), observou uma correlação positiva entre a idade das éguas e a incidência de ovulações multiplas $(P<0,001)$.
O efeito da estação ou mês sobre a taxa de ovulaçбes duplas ou nascimento de gêmeos, foi relatada por HUGHES et al. (1972) e LOY (1980), respectivamente. HENRY (1981), apesar de não ter encontrado um efeito significativo, observou uma maior incidência, aparente, nos meses de abril, agosto e setembro e menor em janeiro.

A principal consequência esperada de uma ovulação múltipla é a ocorrência de gestacão gemelar, entretanto, há uma disparidade entre a freqüência média de ovulações múltiplas registradas na bibliografia (NEELY et al., 1983) de $16 \%$ e a ocorrência de partos gemelares de 1 a $2 \%$ (GINTHER \& DOUGLAS, 1982). Segundo ROBERTS (1986), 95\% das éguas que apresentam ovulação múltipla perdem um ou ambos embrióes numa fase bem precoce da gestação. As éguas que conseguem levar adiante uma gestação gemelar, geralmente abortam entre 8 e 10 meses. Quando levam a gestação a termo, um ou ambos fetos morrem por debilidade resultante de uma provável má nutrição do feto por insuficiência placentária (NEELY et al., 1983). O resultado é sempre negativo, pois perde-se um ano de produção da égua, quando ocorre o aborto ou morte do(s) potro(s) durante o parto; pode haver distocia, risco de vida para a égua, ou então infertilidade e, muitas vezes, esterilidade (ROBERTS, 1971).

Considerando-se os malefícios decorrentes da ovulação múltipla na espécie eqüina, é objetivo deste trabalho documentar a freqüência desse fenômeno fisiológico em éguas de matadouro, onde predominam animais da raça Crioula, criados no Rio Grande do Sul, Brasil (latitude $27^{\circ}$ a $34^{\circ} \mathrm{S}$ ).

\section{MATERIAL E MÉTODOS}

O presente trabalho dispõe de dados de 20 meses de observações. Foram examinadas genitálias de 3631 éguas de janeiro de 1988 a setembro de 1989. Foram coletados, semanalmente, os tratos reprodutivos, incluindo ovários, oviductos, útero e cérvix, de 4016 éguas abatidas no Frigorífico Equus, situado na cidade de Pelotas, Rio Grande do Sul (latitude $27^{\circ}$ a $34^{\circ} \mathrm{S}$ ). Esses animais eram procedentes do Estado do Rio Grande do Sul, com raça predominante da cruza Crioula. As genitálias foram coletadas imediatamente após o abate e examinadas nas dependências do frigorífico.

Do total de éguas, as gestantes, as imaturas, as jumentas e as mulas não foram consideradas para a avaliação. Nas restantes foram avaliados os ovários, utero e cérvix. Durante o exame macroscópico as genitálias foram identificadas em ordem seqüencial e por datas. Os ovários foram dissecados, liberados do oviducto, bursa e ligamentos suspensórios, identificados em esquerdo e direito, de acordo com a posição ventral do ligamento intercornual e então foram seccionados longitudinalmente, através da fossa ovu- 
latória, para verificação da presença e número de corpos lateos (CL's).

As ovulações foram classificadas em simples (presença de um CL em um dos ovários) ou múltiplas (duplas, tríplas e quádruplas, segundo a presença de 2,3 ou 4 CL's em um ou ambos os ovários). Fez-se também o registro da localização destes CL's entre os ovários esquerdo e direito.

\section{Análise Estatística}

Foram estabelecidas as freqüências de éguas com um corpo láteo (taxa de ovulação simples) e éguas com mais de um corpo lúteo (taxa de ovulação múltipla).

0 estudo do efeito do mês sobre as taxas de ovulações múltiplas, foi realizado pela análise de regresão harmônica (Amaral, 1968).

\section{RESULTADOS}

As incidências das ovulações simples e múltiplas estão contidas na Tabela 1 . Houve um efeito significativo $(\mathrm{P}<0,0001)$ do mês sobre as taxas de ovulações múltiplas. A equação que descreve a curva de ovulações múltiplas, por mês no decorrer do ano, é:

$$
Y=7,3833+7,2441 \operatorname{sen}(30 \mathrm{i}+21,406) \text {. }
$$

Observou-se uma prevalência de ovulaçðes simples $(29,6 \%)$ em relação às múltiplas $(7,1 \%)$ (Tabela 1$)$, sendo que estas altimas foram mais comumente bilaterais $(171 / 257$, Tabela 2).
Tabela 2. Distribuição das ovulaçðes simples e múltiplas entre $\infty$ ovários esquerdo (OE) e direito (OD).

\begin{tabular}{llccc}
\hline Tipo de & Ovário & Ovário & OE + OD & Total \\
Ovulação & $\begin{array}{c}\text { Esquerdo } \\
(\%)\end{array}$ & $\begin{array}{c}\text { Direito } \\
(\%)\end{array}$ & $(\%)$ & $(\%)$
\end{tabular}

\begin{tabular}{lcccr}
\hline & & & & \\
Simples & $566(52,65)$ & $509(47,34)$ & --- & 1,075 \\
Duplas & $37(15,74)$ & $43(19,29)$ & $155(65,95)$ & 235 \\
Tríplas & $4(21,05)$ & $1(5,26)$ & $14(76,69)$ & 19 \\
Quádruplas & $-\ldots-\cdots$ & $-\cdots(100,00)$ & 3 \\
\hline
\end{tabular}

$\begin{array}{lllll}\text { TOTAL } & 597(45,00) & 553(42,00) & 172(13,00) & 1,332\end{array}$

Os meses de maior e menor incidência de ovulação simples foram janeiro $(65,3 \%)$ e agosto $(2,4 \%)$, respectivamente. Para ovulaçðes multiplas o mês de maior incidencia foi fevereiro (19\%) e o de menor foi setembro $(0,4 \%)$

Do total de 257 ovulações múltiplas, 235 $(91,44 \%)$ foram duplas, $19(7,4 \%)$ tríplas e $3(1,17 \%)$ quádruplas.

Em relação à distribuição das ovulações simples e multiplas entre os ovários, se observou uma atividade do ovário esquerdo de $45 \%$ (597/1332) e do direito de $42 \%$ (553/1332) (Tabela 2).

A freqüência de ovulações tríplas e quádruplas, do total de ovulaçðes foi de $1,43 \%$ (19/1332) e $0,23 \%$ $(3 / 1332)$, respectivamente.
Tabela 1. Taxa de Ovulação Simples e Múltipla.

\begin{tabular}{|c|c|c|c|c|c|c|c|}
\hline \multirow[b]{2}{*}{ Mês } & \multirow[b]{2}{*}{$\mathrm{N}^{\mathrm{o}}$ Eguas } & \multirow[b]{2}{*}{$\begin{array}{l}\mathrm{c} / \mathrm{CL} \\
(\%)\end{array}$} & \multirow[b]{2}{*}{$\begin{array}{c}\text { Simples } \\
(\%)\end{array}$} & \multicolumn{4}{|c|}{ Múltiplas } \\
\hline & & & & $\begin{array}{c}\text { Dupla } \\
(\%)\end{array}$ & $\begin{array}{l}\text { Tripla } \\
(\%)\end{array}$ & Quadiupla & $\begin{array}{c}\text { Total } \\
(\%)\end{array}$ \\
\hline Jan & 199 & $147(73,9)$ & $130(65,3)$ & $15(7,5)$ & $2(1,0)$ & - & $17(8,5)$ \\
\hline Fev & 300 & $250(83,3)$ & $193(64,3)$ & $52(17,3)$ & $4(1,3)$ & $1(0,3)$ & $57(19,0)$ \\
\hline Mar & 296 & $185(62,5)$ & $145(49,0)$ & $37(12,5)$ & $3(1,0)$ & - & $40(13,5)$ \\
\hline Abr & 270 & $135(50,0)$ & $103(38,1)$ & $30(11,1)$ & $2(0,7)$ & - & $32(11,9)$ \\
\hline Mai & 352 & $88(25,0)$ & $66(18,7)$ & $21(6,0)$ & $1(0,3)$ & - & $22(6,3)$ \\
\hline Jun & 388 & $79(20,4)$ & $54(13,9)$ & $20(5,1)$ & $4(1,0)$ & $1(0,3)$ & $25(6,4)$ \\
\hline Jul & 556 & $35(6,3)$ & $30(5,4)$ & $5(0,9)$ & - & - & $5(0,9)$ \\
\hline Ago & 375 & $13(3,5)$ & $9(.2,4)$ & $4(1,1)$ & - & - & $4(1,1)$ \\
\hline Set & 264 & $18(6,8)$ & $17(6,4)$ & $1(0,4)$ & - & - & $1(0,4)$ \\
\hline Out & 106 & $18(17,0)$ & $14(13,2)$ & $4(3,9)$ & - & - & $4(3,8)$ \\
\hline Nov & 192 & $122(63,5)$ & $114(59,4)$ & $7(3,6)$ & $1(0,5)$ & - & $8(4,2)$ \\
\hline Dez & 333 & $242(72,7)$ & $200(60,0)$ & $39(11,7)$ & $2(0,6)$ & $1(0,1)$ & $42(12,6)$ \\
\hline
\end{tabular}

Total $\quad 3,631 \quad 1,332(36,7) \quad 1,075(29,6) \quad 235(6,5) \quad 19(0,5) \quad 3(0,1) \quad 257(7,1)$

\section{DISCUSSÃO}

Um aspecto interessante da fisiologia reprodutiva da égua é a alta freqüência de ovulações múltiplas que, segundo GINTHER (1979), pode atingir até $44 \%$. Pela Tabela 1 , podemos observar que a incidência de ovulações múltiplas durante o ano foi de 7,1\%. Este resultado é concordante com os resultados obtidos por SILVA et al. $(1988 ; 6,97 \%)$, porém mais baixo que o relatado por ARTHUR $(1958 ; 18,5 \%)$, OSBORNE (1966; 14,5\%), RESENDE (1974; $34,5 \%)$, WARSZAWSKY et al. (1972; $42,8 \%)$, SALTIEL et al. (1982; 11,9\%), HENRY $(1981 ; 21,5 \%)$ e WESSON \& GINTHER $(1981 ; 10 \%)$, estudos estes, onde foi utilizado material de matadouro. Estas diferenças, segundo GINTHER (1986), podem ser atribuídas a fatores tais como raça, idade, 
repetibilidade e "status" reprodutivo, uma vez que a mesma metodologia foi empregada. HENRY (1981) constatou que a incidencia de ovulações máltiplas pode variar com a idade ou raça. Nesse trabalho, a influência da idade não foi significativa dentro das raças, entretanto, ao considerar todos os animais (raças diferentes), um aumento gradual significativo $(\mathrm{P}<0,005)$ foi notado nas éguas com mais idade. Quando todas as idades foram combinadas, os índices de ovulaçðes múltiplas foram significativamente $(P<0,005)$ diferentes entre raças (HENRY, 1981). Além da raça e idade, deve-se considerar que algumas éguas, individualmente, podem ovular dois folículos e gestarem gêmeos com mais freqüência do que outras (BURKHARDT, 1948; GINTHER, 1986). HENRY (1981), comenta que diferentes sistemas de manejo, incluindo alimentação, podem contribuir para a variabilidade observada nas taxas de ovulações multiplas. A diferença encontrada neste trabalho, em relação ao relatado pelos autores já citados, poderia ser devida ao fato de que compreendiam animais de diferentes raças que não a Crioula, submetidos a diferentes sistemas de manejo e alimentação. Já a semelhança do resultado obtido por SILVA et al. (1988), pode ter sido devida ao fato de que $70 \%$ das éguas examinadas em seu estudo eram procedentes da mesma região onde se realizou o presente trabalho. Um efeito dos meses do ano (Tabela 1) sobre a incidência de ovulações múltiplas foi observado $(P<0,0001)$ e a variação das percentagens mensais foi semelhante a taxa de ovulação geral observada por TAROUCO (1992), indicando que os mesmos fatores que determinam a estacionalidade na taxa de ovulação também influenciam os índices de ovulação multipla. Uma influência negativa do inverno (fotoperíodo mais curto e temperaturas mais baixas) sobre esta taxa, está de acordo com as observaç⿸̃es de BURKHARDT (1948), ARTHUR (1958), ARTHUR (1969), HUGHES et al.(1972) e SALTIEL et al. (1982). Os índices mais elevados se concentraram nos meses de dezembro a abril e os mais baixos, de maio a novembro (Tabela 1), observação esta, que pode proporcionar um importante subsídio para o criador de animais da raça Crioula que pretendem elevar a eficiência reprodutiva, controlando, através do manejo reprodutivo (estabelecimento da estação reprodutiva) a possível freqüência de gestaçőes gemelares. $\mathrm{O}$ conhecimento da freqüência de ovulações múltiplas em animais com predominância da raça Crioula, pode também contribuir para a identificação de possíveis causas de infertilidade na raça, já que a principal causa de abortos na espécie equina é a gestação gemelar e desse aborto, podem resultar alterações inflamatórias genitais além de outras lesðes.

As taxas de ovulações múltiplas mais elevadas foram registradas durante o verão (Tabela 1). Já, OSBORNE (1966), encontrou índices maiores durante a primavera (GREENHOFF \& KENNEY, 1975), enquanto HENRY (1981), no Hemisfério Norte, concluiu que não houve in- fluência da estação sobre a incidência de ovulaçðes máltiplas, embora o segundo autor tenha observado uma tendência aparente de taxas maiores no verão (abril, agosto e setembro) e menores durante o inverno (janeiro). A prevalência de ovulações duplas sobre tríplas e quádruplas (Tabela 1), considerando o total de ovulações múltiplas também obedeceu a estacionalidade (Tabela 1) e sua percentagem total de ocorrência, concorda com o reportado por OSBORNE (1966) com $95 \%$ duplas, $4,8 \%$ triplas e $0,25 \%$ quádruplas, por HENRY (1981) com 94,2\% duplas, 5,6\% triplas e $0,2 \%$ quádruplas, e por SALTIEL et al. (1982) com $88,5 \%$ duplas e $11,5 \%$ triplas. Numa população de éguas com predominância da raça Crioula, como a deste trabalho, a freqüência de ovulações múltiplas foi mais baixa do que a menor freqüência considerada para Pôneis, 8 a $10 \%$ (GINTHER, 1986), e pode representar um importante aspecto no que se refere à seleção e manejo reprodutivo, já que esta é uma característica indesejável e possivelmente hereditária (ROBERTS, 1971).

\section{REFERÊNCIAS BIBLIOGRÁFICAS}

AMARAL, E. Análise Harmônica. Pesq Agropec Bras, v. 3, p. 7-43, 1968.

ARTHUR, G.H. An analysis of the reproductive function of mares based on post mortem examination. Vet Rec, London, v. 170, p. 682-686, 1958.

ARTHUR, G.H. The ovary in the mare in health and disease. Equine Vet J, v. 1, p. 153-156, 1969.

BELLING, T.H. Reproduction in the mare. Equine Practice, v. 5, p. 13-18, 1983.

BURKHARDT, J. Transition from anestrous in the mare and the effects of artificial lighthing. J Agric Sci, v. 37, p. 64-68, 1948.

DESKUR, S. Twinning in Thoroughbred mares in Poland. Theriogenology, v. 23, p. 711-718, 1985 .

GINTHER, OJ. Reproductive biology of the mare: basic and applied aspects. Mc Naughton and Gunn. Inc. Ann. Arbor. Michigan, U.S.A., 1979. $413 \mathrm{p}$.

GINTHER, O.J. Twinning in mares. A review of recent studies. J Equine Vet Sci, v. 21, p. 127-135, 1982.

GINTHER, O.J. Ultrasonic Imaging and Reproductive and Reproductive Events in the Mare. Equiservises, Cross Plains, Wisconsin. 1986. $378 \mathrm{p}$.

GINTHER, O.J., DOUGLAS, R.H., LAWRENCE, J.R. Twinning in mares: A survey of veterinarians and analyses of theriogehology records. Theriogenhology, v. 18, p. 333-347, 1982. 
GINTHER, O.J., DOUGLAS, R.H. The outcome of tw in pregnancies in the mare. Theriogenology, v. 18, p. 237-244, 1982.

GREENHOFF, G.R., KENNEY, R.M. Evaluation of reproductive status of non-pregnant mares. J Am Vet Med Assoc, v. 167, p. 449, 1975.

HENRY, M.R.J.M. 1981. Some Special Aspects of the Physiopathology of Reproduction in Mares. Gent 219 p. Tese (Doutorado), Universidade de Gent, Bélgica. 1981.

HENRY, M., CORYN, M., VANDEPLASSCHE, M. Múltiple ovulation in the mare. Zbl Vet Med, v. 29, p. 170-184, 1982.

HUGHES, J.P., STABENFELDT, G.H., EVANS, J.W. Estrous cycle and ovulation in the mare. J Am Vet Med Assoc, v. 161, p. $1367-1374,1972$.

LOY, R.G. Characteristics of postpartum reproduction mares. Vet Clin of North Amer: Large Anim Pract, v. 2, p. 345-359, 1980.

NEELY, D.P. Reproductive endocrinology and fertility in the mare. In: NEELY, LIU, HILLMAN. Equine Reproduction. Vet. Learning Systems Co., 1983. INC. p. 12-22.

OSBORNE, V.E. An analysis of the pattern of ovulation as it occurs in the annual reproductive cycle of the mare in Australia. Aust Vet $J, v .42$, p. $149-154,1966$.

RESENDE, J. Atividade ovariana em éguas abatidas em matadouro, durante as fases do ciclo estral, nas estacóes seca e chuvosa, em Minas Gerais. Belo Horizonte. 132 p. Tese (Mestrado) U.F.M.G., Minas Gerais, 1974.
ROBERTS, S.J. Veterinary Obstetrics and Genital Diseases. 2a. Ed. Ann Arbor, Michigan, Edward Brothers Inc. 1971. 776 p.

ROBERTS, SJ. Abortion and Other Gestational Diseases in Mares. In: MORROW, D.A. Current Therapy in Theriogenology - $22 \mathrm{a}$. ed. W. B. Saunders Co. Philadelphia. 1986. p. 705-710.

SALTIEL, A., CALDERON, A., GARCIA, N., et al. Ovarian activity in the mare between latitude $15^{\circ}$ and $22^{\circ} \mathrm{N}$. J Reprod Fert, Suppl, v. 32, p. 261-267, 1982.

SILVA, C.A.M., de ALDA, J.L., de SÁ, J.E.C., et al. Características da curva ovulatória estacional em éguas de abate na região Sul do Brasil. Pesq Vet Bras, v. 8, p. 57-60, 1988.

STABENFELDT, G.H., HUGHES, J.P., EVANS, J.W., et al. Unique aspects of the reproductive cycle of the mare. J Reprod Fert, Suppl, v. 23, p. $155-160,1975$.

TAROUCO, A.K. Estacionalidade reprodutiva de éguas abatidas em Pelotas - RS. Pelotas, RS. 80 p. Tese (Mestrado). Curso de Pós-graduação em Medicina Veterinária. Universidade Federal de Pelotas. 1992.

WARSZAWSKY, L.F., PARKER, W.G., FIRST, N.L., et al. Gross changes of internal genitalia during the estrous cycle of the mare. Am J Vet Res, v. 33, p. 19-26, 1972.

WESSON, J.A., GINTHER, O.J. Influence of season and age on reproductive activity in pony mares on the basis of a slaughterhouse study. $J$ Anim Sci, v. 52, p. 119-129, 1981. 